\title{
Bone health assessment in haemophilic arthropathy: A single centre study from Kolkata, West Bengal, India
}

Prakas Kumar Mandal, Malini Garg, Prantar Chakrabarti, Amrita Bhowmik, Debasis Gantait, Tuphan Kanti Dolai

Background: Haemophilia has been associated with increased prevalence of low bone mineral density (BMD) which in turn may aggravate haemophilic arthropathy. Dual-energy X-ray absorptiometry (DEXA) is the gold standard for assessing BMD but is not widely available across India. Markers of bone turnover like bone-specific alkaline phosphatase (b-ALP) reflect osteoblastic turnover and may be surrogate to low BMD. Aim: To evaluate how bone health in people with haemophilia (PWH) can be assessed by serum vitamin D3 and b-ALP level, correlated with the degree of arthropathy. Methods: In this cross-sectional study,

PRAKAS KUMAR MANDAL

Department of Hematology, NRS Medical College,

Kolkata, India. Email: pkm.hem@gmail.com

MALINI GARG

Department of Hematology, NRS Medical College,

Kolkata, India

PRANTAR CHAKRABARTI

Department of Hematology, NRS Medical College, Kolkata, India

AMRITA BHOWMIK

Department of Hematology, NRS Medical College, Kolkata, India

\section{DEBASIS GANTAIT}

Department of Hematology, NRS Medical College, Kolkata, India

\section{TUPHAN KANTI DOLAI}

Department of Hematology, NRS Medical College, Kolkata, India

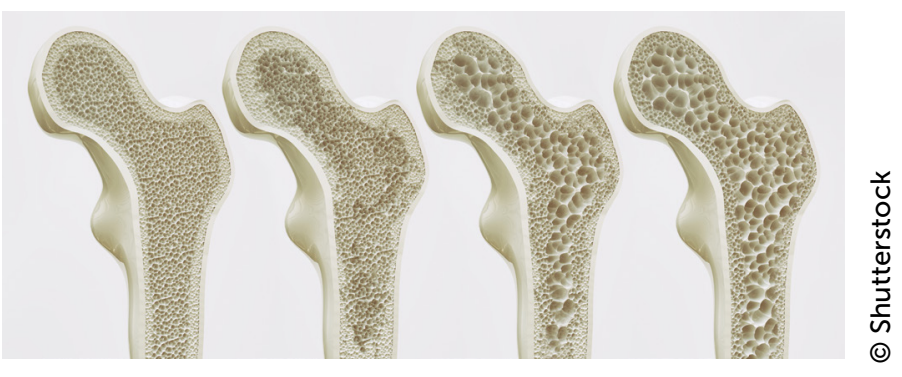

Measuring bone mineral density is key to determining the risk and presence of osteoporosis, a potential comorbidity for people with haemophilia linked to joint bleeds, inflammation and arthropathy. In countries where DEXA scanning facilities are not widely available, bone turnover markers like b-ALP may be useful in assessing joint health.

people with haemophilia A and B of all severities with arthropathy involving $\geq 3$ joints were included. The number of joints affected by haemophilic arthropathy was recorded. Hemophilia Joint Health Score (HJHS) and Pettersson score were calculated for each patient. Levels of serum calcium, phosphorus, vitamin D3 and b-ALP were assayed in all cases. Results: A total of 320 PWH were included; the majority $(85 \%$; $272 / 320)$ had severe haemophilia, $13.44 \%$ (43/320) moderate haemophilia and $1.56 \%$ (5/320) mild haemophilia. With increasing age, the number of joints involved increased significantly $(r=0.2250, p<0.05)$. When adjusted for age, b-ALP was higher than normal for the majority of PWH (88.75\%). Increased number of joints involved and severity of disease had a positive correlation with higher-than-normal b-ALP (adjusted for age) ( $r=0.2112$,

This is an Open Access article distributed under the terms of the Creative Commons Attribution-NonCommercial-NoDerivs License (https://creativecommons.org/licenses/by-nc-nd/3.0/) which permits use and distribution in any medium, provided the original work is properly cited, the use is non-commercial, and no modifications or adaptations are made. Copyright is retained by the authors. 
$p=0.0001)$. A significant positive correlation was seen between Pettersson score and HJHS score $(r=0.1126$, $p=0.04$ ). There was no significant correlation between number of joints involved and serum vitamin D3 level across the whole cohort. $(\mathrm{p}<0.05)$. Conclusion: PWH with severe disease and haemophilic arthropathy have higher than normal $b-A L P$, which in turn reflects increased bone turn over and low BMD. Hence, b-ALP may be a useful marker to help assess bone health in $\mathrm{PWH}$, particularly in settings where access to DEXA scans is constrained.

Keywords: Haemophilic arthropathy, Bone health in haemophilia, Pettersson score, Hemophilia Joint Health Score

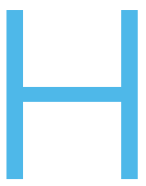

aemophilia is an $\mathrm{X}$-linked recessive bleeding disorder. Haemophilia A and $B$ are characterised by deficiency of factors VIII (FVIII) and IX (FIX) respectively.

Deficiency of coagulation factors leads to spontaneous intra-articular haemorrhage, resulting in cartilage destruction, inflammatory infiltration of the synovial membrane and iron deposition, a condition known as haemophilic arthropathy ${ }^{[1]}$. Haemophilic arthropathy has been shown to have a negative impact on quality of life ${ }^{[2-4]}$. Haemophilia has also been associated with increased prevalence of low bone mineral density (BMD), both in adults and children ${ }^{[5-8]}$. Low BMD has been attributed to many pathogenic mechanisms in people with haemophilia ( $\mathrm{PWH}$ ), including avoidance of weight-bearing exercise due to the fear of haemorrhage and reduced physical activity due to arthropathy. Thus these parameters negatively impact the acquisition of peak bone mass in these patients ${ }^{[9]}$. Other covariates involved in the pathogenesis of low BMD in PWH include hepatitis $\mathrm{C}(\mathrm{HCV})$ and human immunodeficiency virus (HIV) infections ${ }^{[5-8]}$.

In studies showing decreased BMD among PWH the prevalence of osteopenia and osteoporosis has been variable ${ }^{[5,8,10-16]}$. However, low bone mass (osteopenia and osteoporosis combined) was found in $22-84 \%$ of all patients ${ }^{[10-16]}$. This increases the risk of fractures ${ }^{[17,18]}$. The main technology used to study BMD is dual-energy $\mathrm{X}$-ray absorptiometry (DEXA), which is considered worldwide as the gold standard for the assessment of BMD and diagnosis of osteoporosis. The majority of studies on assessment of bone health in haemophilia have used DEXA scans.

Studies of BMD in India are limited ${ }^{[10,19]}$. Furthermore, DEXA facilities are not widely available across the country and are costly where they are available ${ }^{[20]}$. Bone turnover markers (BTM) such as bone-specific alkaline phosphatase ( $b$-ALP) may be useful in assessing bone health in $\mathrm{PWH}{ }^{[21]}$. BTMs are biochemical products reflecting the metabolic activity of bone. They are divided into two categories, representing either bone formation or bone resorption ${ }^{[22]}$. B-ALP, a membrane-bound tetrameric enzyme located on the outer cell surface of osteoblasts ${ }^{[23]}$, is a bone turnover marker that reflects osteoblastic turnover and may be surrogate to low BMD. The present study assesses bone health in PWH by serum vitamin D3 and b-ALP level, correlated with the degree of arthropathy both clinically and radiologically.

\section{METHODS}

In this cross-sectional study, PWH with arthropathy involving $\geq 3$ joints attending the haemophilia clinic at Nil Ratan Sircar Medical College and Hospital, Kolkata, over a period of five years from January 2016 to December 2020 were included. People with haemophilia A and haemophilia B of all severities without inhibitors were included in the study. The included PWH were divided into four groups

Table 1. Parameters included in Pettersson score ${ }^{[18]}$

\begin{tabular}{|c|c|c|}
\hline $\begin{array}{l}\text { RADIOGRAPHIC } \\
\text { PARAMETER }\end{array}$ & FINDING(S) & SCORE \\
\hline Osteoporosis & $\begin{array}{l}\text { Absent } \\
\text { Present }\end{array}$ & $\begin{array}{l}0 \\
1\end{array}$ \\
\hline Enlarged epiphysis & $\begin{array}{l}\text { Absent } \\
\text { Present }\end{array}$ & $\begin{array}{l}0 \\
1\end{array}$ \\
\hline $\begin{array}{l}\text { Irregular subchondral } \\
\text { surface }\end{array}$ & $\begin{array}{l}\text { Absent } \\
\text { Slight } \\
\text { Pronounced }\end{array}$ & $\begin{array}{l}0 \\
1 \\
2\end{array}$ \\
\hline Narrowing of joint space & $\begin{array}{l}\text { Absent } \\
<50 \% \\
>50 \%\end{array}$ & $\begin{array}{l}0 \\
1 \\
2\end{array}$ \\
\hline $\begin{array}{l}\text { Subchondral cyst } \\
\text { formation }\end{array}$ & $\begin{array}{l}\text { Absent } \\
\text { One cyst } \\
\text { More than one cyst }\end{array}$ & $\begin{array}{l}0 \\
1 \\
2\end{array}$ \\
\hline Erosions at joint margins & $\begin{array}{l}\text { Absent } \\
\text { Present }\end{array}$ & $\begin{array}{l}0 \\
1\end{array}$ \\
\hline $\begin{array}{l}\text { Gross incongruence } \\
\text { of articulating bone } \\
\text { ends (angulation/ } \\
\text { displacement) }\end{array}$ & $\begin{array}{l}\text { Absent } \\
\text { Slight } \\
\text { Pronounced }\end{array}$ & $\begin{array}{l}0 \\
1 \\
2\end{array}$ \\
\hline Joint deformity & $\begin{array}{l}\text { Absent } \\
\text { Slight } \\
\text { Pronounced }\end{array}$ & $\begin{array}{l}0 \\
1 \\
2\end{array}$ \\
\hline
\end{tabular}


Table 2. Distribution of joint health scoring and biochemical parameters in different age groups

\begin{tabular}{|c|c|c|c|c|}
\hline AGE GROUPS & $\begin{array}{l}1 \text { TO } 5 \text { YEARS } \\
(\mathrm{N}=21)\end{array}$ & $\begin{array}{l}>5 \text { TO } 10 \text { YEARS } \\
(\mathrm{N}=67)\end{array}$ & $\begin{array}{l}>10 \text { TO } 15 \text { YEARS } \\
(N=66)\end{array}$ & $\begin{array}{l}>15 \text { YEARS } \\
(N=166)\end{array}$ \\
\hline $\begin{array}{l}\text { No. of joints affected } \\
\text { (mean } \pm \text { SD) }\end{array}$ & $3.81 \pm 1.47$ & $4.88 \pm 2.25$ & $5.22 \pm 2.29$ & $5.56 \pm 2.37$ \\
\hline HJHS (mean \pm SD) & $13.71 \pm 2.81$ & $14.29 \pm 2.39$ & $14.60 \pm 2.24$ & $14.26 \pm 2.37$ \\
\hline Peterson score (mean \pm SD) & $10.14 \pm 1.45$ & $9.76 \pm 1.98$ & $10.12 \pm 1.6316$ & $10.13 \pm 1.81$ \\
\hline Calcium (mean \pm SD) & $9.91 \pm 0.50$ & $9.66 \pm 0.62$ & $9.77 \pm 0.60$ & $9.53 \pm 0.58$ \\
\hline $\begin{array}{l}\text { Low serum calcium } \\
\text { (age/sex adjusted) }\end{array}$ & $0 \%(0 / 21)$ & $8.9 \%(6 / 67)$ & $6.06 \%(4 / 66)$ & $21.08 \%(35 / 166)$ \\
\hline Phosphorus (mean \pm SD) & $4.42 \pm 0.73$ & $4.57 \pm 0.65$ & $3.95 \pm 0.80$ & $3.56 \pm 0.61$ \\
\hline $\begin{array}{l}\text { Low serum phosphorus } \\
\text { (age/sex adjusted) }\end{array}$ & $28.57 \%(6 / 21)$ & $17.91 \%(12 / 67)$ & $13.63 \%(9 / 66)$ & $9.03 \%(15 / 166)$ \\
\hline Vitamin D3 (ng/dl);(mean \pm SD) & $12.88 \pm 5.24$ & $14.84 \pm 7.21$ & $16.35 \pm 9.31$ & $17.04 \pm 7.57$ \\
\hline $\begin{array}{l}\text { Low vitamin D3 (<20 ng/dl); } \\
(\%(n))\end{array}$ & $90 \%(18 / 21)$ & $82.09 \%(55 / 67)$ & $71.2 \%(47 / 66)$ & $71.69 \%(119 / 166)$ \\
\hline b-ALP (ug/L); (mean \pm SD) & $116.67 \pm 11.2$ & $149.62 \pm 23.09$ & $197.95 \pm 29.02$ & $42.07 \pm 29.691$ \\
\hline $\begin{array}{l}\text { High b-ALP (age/sex adjusted); } \\
(\%(n))\end{array}$ & $76.19 \%(16 / 21)$ & $86.57 \%(58 / 67)$ & $80.33 \%(53 / 66)$ & $94.57 \%(157 / 166)$ \\
\hline ALP (U/L); (mean \pm SD) & $119.42 \pm 18.92$ & $103.79 \pm 20.73$ & $117.09 \pm 24.61$ & $104.75 \pm 23.72$ \\
\hline
\end{tabular}

according to age and the number of joints affected by haemophilic arthropathy was recorded. Hemophilia Joint Health Score (HJHS) (clinical scoring system) and Pettersson score (radiological scoring system) for the target joints were calculated for each patient.

HJHS 2.1 is the most recent version and consists of assessments of swelling (0-3), duration of swelling $(0-1)$, muscle atrophy (0-2), crepitus on motion (0-2), flexion loss (0-3), extension loss ( $0-3)$, joint pain $(0-2)$ and strength (0-4) for elbows, knees and ankles and a global gait score (0-4). Scores range from 0 to 20 per joint and the global gait score ranges from 0 to 4 , resulting in a total HJHS score from 0 to 24 points ${ }^{[2,25]}$.

The Pettersson score covered eight parameters scored on radiographs of the affected joint taken in two planes (Table 1). The extent of irreversible joint changes was assessed by scoring each of the parameters on a 0-2-point scale. Essentially reversible findings such as soft tissue swelling or synovial thickening were disregarded. The maximum possible score for a given joint was 13 points [26].

Levels on serum calcium, phosphorus, vitamin D3 and $b$-ALP were assayed in all cases. The percentage of PWH with low serum calcium, low phosphorus levels, low vitamin D3 levels or high b-ALP levels adjusted for age and sex were calculated, according to the standard reference range. Data was analysed using Pearson's correlation coefficient $(r)$ and $p$-value $<0.05$ was taken as statistically significant.

\section{RESULTS}

A total of 320 PWH were included in the study. The median age was 17 years (range $1-70$ years). Overall, $78.13 \%$ (250/320) had haemophilia A; $21.87 \%$ (70/320) had haemophilia B. The majority $(85 \% ; 272 / 320)$ had severe haemophilia; $13.44 \%(43 / 320)$ had moderate haemophilia; 1.56\% (5/320) had mild haemophilia. At the time of examination and evaluation, $34.37 \%$ (110/320) were on prophylaxis; the remainder were on on-demand therapy.

Table 2 shows joint health scoring and biochemical parameters across the different age groups. With increasing age, the number of joints involved increased significantly $(r=0.2250, p<0.05)$. When adjusted for age, b-ALP was higher than normal for the majority of PWH (88.75\%). Also, a positive correlation was seen between higher-than-normal b-ALP (adjusted for age and sex) with increased number of joint involvement $(r=0.2112, p=0.0001)$ and severity of disease $(r=0.2652$ $\mathrm{p}<0.0001)$. Patients with a higher Pettersson score also had higher than normal $b$-ALP, though the result was not statistically significant $(r=0.0994, p=0.0758)$. There was no association between b-ALP and HJHS score. PWH with higher-than-normal b-ALP had lower calcium $(r=-0.0909, p=0.1048)$ and phosphorus levels $(r=-0.0256 p=0.6484)$, although the difference was not statistically significant. A significant positive correlation was seen between Pettersson score and HJHS score ( $r$ score $0.1126, p=0.04$ ). No correlation was seen 
between Pettersson score or HJHS score with calcium, phosphorus or vitamin $D$ levels $(p<0.05)$. There was no significant correlation between the number of joints involved, severity of disease and serum vitamin D3 level across the whole cohort.

\section{DISCUSSION}

Osteoporosis in general has been considered to be an important cause of morbidity in both men and women, and more so in haemophilia and other bleeding disorders. Specific triggering factors in PWH include abnormal liver function because of viral infection, bleeding and inflammation, lack of physical and athletic activities, low body weight and others ${ }^{[27]}$. Although the pathogenesis of osteoporosis is not clear, it has been considered as a severe comorbidity in PWH in both developing and developed countries. This is more evident in developing countries where there is limited access to factor concentrates, and primary prophylaxis is beyond the reach of vast majority of the patients ${ }^{[27]}$. In the present study, the majority of patients were on on-demand therapy and not on regular prophylaxis.

The present study indicates a positive association between b-ALP (adjusted for age and sex), a marker that indicates high bone turnover with number of affected joints and severity of the disease. Similar to the present study, Anagnostis et al. ${ }^{[21]}$ found a positive association of b-ALP with the severity of haemophilia and number of affected joints. They found a negative association with BMD in hip and femoral neck, history of fracture, and level of physical activity, though these points were not evaluated in the present study. Anagostis et al. also reported that b-ALP was high in patients who had low BMD [21].

Our study found a radiological and clinical correlation, with patients who had a high Pettersson score on X-ray also having a high HJHS score on clinical examination. Poonnoose et al. ${ }^{[28]}$ also showed a good correlation between HJHS and Pettersson score $(r=0.66)$. PWH in the present study with a high Pettersson score also had high b-ALP, although the results were not statistically significant. This indicates that b-ALP may be of help in evaluating bone health in PWH, though more studies are needed to further establish the association. We could not find any similar studies in haemophilia from this geographic region.

Many studies have shown PWH to have low BMD. Barnes et al. ${ }^{[11]}$ showed significantly reduced BMD in PWH. Mansouritorghabeh et al. [12] showed that BMD is significantly reduced even in cases of severe haemophilia $B$, and the effect on BMD is not dependent on the severity of haemophilia ${ }^{[11,12]}$. PWH with low BMD have been found to have reduced bone formation activity but no difference with regard to bone resorption markers ${ }^{[13]}$. Abdelrazik et al. ${ }^{[14]}$ showed that reduction in $\mathrm{BMD}$ is not dependent on age and body size. Naderi et al. ${ }^{155}$ have reported that bleeding into the joints is more pronounced in osteoporotic patients compared with osteopenic or normal healthy controls. Wallny et al. ${ }^{16]}$ reported osteopenia and osteoporosis in $69 \%$ of people with severe haemophilia. However, the majority of these studies used DEXA scans as the technique to evaluate the BMD.

We are aware of two studies in India where DEXA scans have been used to measure BMD in relatively small cohorts. Nair et al. ${ }^{[10]}$ found that in 50 people with severe haemophilia aged 20-50 the prevalence of osteoporosis was 50\% higher than in age- and sexmatched controls; they concluded that developing osteoporosis is a significant problem for people with severe haemophilia in India. In a cohort of 38 children with haemophilia (>18 years), Ashritha et al. ${ }^{[19]}$ found low bone mineral content in 58\% and low BMD in 21\% compared with age- and sex-matched controls.

We were unable to use DEXA to calculate BMD in our study as, in common with many hospitals in India, there are no DEXA facilities in our hospital. Availability of DEXA in India has been given as between 200 and 300 machines nationally to serve a population of 1.3 billion ${ }^{[20]}$. Even where DEXA is available, scans are costly and not always covered by healthcare schemes. It is therefore important that alternative, cost-effective tools that are more readily available can be used to assess BMD. Various studies have shown an association between high b-ALP and low BMD, indicating high b-ALP as a surrogate marker for low BMD ${ }^{[21,29]}$. However, few studies have evaluated b-ALP in haemophilia and compared this with clinical or radiological scoring for bone arthropathy. It is clear from our findings that b-ALP might serve as a surrogate marker to assess bone health in PWH in clinics where DEXA is not available. Further studies including other bone markers are required to further establish this fact.

\section{Limitations}

Clearly, the principal limitation of our study is that we were not able to compare our findings based on b-ALP assessment with results based on DEXA scans among the same cohort. A further limitation is that we did not include an age- and sex-matched 'healthy' control cohort. We did, however, compare our data with ageand sex-matched reference values. 


\section{CONCLUSION}

PWH with severe disease and haemophilic arthropathy appear to have higher than normal bone-specific ALP (b-ALP), which may in turn reflect increased bone turnover and low bone mineral density (BMD). Hence, b-ALP might serve as a surrogate marker to help assess bone health in $\mathrm{PWH}$, particularly in settings where access to DEXA scans is constrained. Further studies will be needed to confirm this conclusion.

\section{AUTHOR CONTRIBUTIONS}

PKM designed the study. PKM, MG and DG contributed to the manuscript writing, literature search, and manuscript editing. All authors contributed to critical review of the manuscript and final approval.

\section{ACKNOWLEDGEMENTS}

Ethics: The study was reviewed and approved by the Institutional Ethical Committee (IEC) of Nil Ratan Sircar Medical College \& Hospital, Kolkata.

Informed consent: Informed and written consent was obtained from all the study participants.

Conflict of interest: The authors have advised no interests that might be perceived as posing a conflict or bias.

\section{ORCID}

Prakas Kumar Mandal (iD https://orcid.org/0000-0003-2955-3832 Malini Garg (ID) https://orcid.org/0000-0002-8294-5707 Prantar Chakrabarti iD https://orcid.org/0000-0003-1026-5427 Amrita Bhowmik (D) https://orcid.org/0000-0001-6872-9840 Debasis Gantait (D) https://orcid.org/0000-0001-7972-0200 Tuphan Kanti Dolai (iD https://orcid.org/0000-0001-8842-6257

\section{REFERENCES}

1. Hoots K, Rodriguez N, Boggio L, Valentino L. Pathogenesis of haemophilic synovitis: clinical aspects. Haemophilia 2007; 13 Suppl 3: 4-9. doi: 10.1111/j.1365-2516.2007.01533.x.

2. Ucer-Lozano R, López-Pina, JA, Ortiz-Pérez A, CuestaBarriuso R. Quality of life and its predictors among adult patients with haemophilic arthropathy. An observational study. BMC Musculoskelet Disord 2021; 22: 448. doi: 10.1186/ s12891-021-04319-0.

3. Varaklioti A, Kontodimopoulos N, Niakas D, Kouramba A, Katsarou $\mathrm{O}$. Health-related quality of life and association with arthropathy in Greek patients with hemophilia. Clin Appl Thromb Hemost 2018; 24(5): 815-821. doi: 10.1177/1076029617733041.

4. Witkop M,Guelcher C, Forsyth A, et al. Treatment outcomes, quality of life, and impact of hemophilia on young adults (aged 18-30 years) with hemophilia. Am J Hematol 2015; 90 Suppl 2: S3-10. doi: 10.1002/ajh.24220.

5. Anagnostis $P$, Vakalopoulou S, Slavakis A. Reduced bone mineral density in patients with haemophilia $A$ and $B$ in Northern Greece. Thromb Haemost 2012; 107(3): 545-51. doi: 10.1160/TH11-08-05563.
6. Katsarou O, Terpos E, Chatzismalis P, et al. Increased bone resorption is implicated in the pathogenesis of bone loss in hemophiliacs: correlations with hemophilic arthropathy and HIV infection. Ann Hematol 2010; 89(1): 67-74. doi: 10.1007/ s00277-009-0759-x.

7. Iorio A, Fabbriciani G, Marcucci M, Brozzetti M, Filipponi P. Bone mineral density in haemophilia patients. A meta-analysis Thromb Haemost 2010; 103(3): 596-603. doi: 10.1160/TH0909-0629.

8. Gerstner G, Damiano ML, Tom A, et al. Prevalence and risk factors associated with decreased bone mineral density in patients with haemophilia. Haemophilia 2009; 15(2): 559-65. doi: 10.1111/j.1365-2516.2008.01963.x

9. Welten DC, Kemper HC, Post GB, et al. Weight-bearing activity during youth is a more important factor for peak bone mass than calcium intake. J Bone Miner Res 1994; 9(7): 1089-96. doi: 10.1002/jbmr.5650090717.

10. Nair AP, Jijina F, Ghosh K, Madkaikar M, Shrikhande M, Nema $M$. Osteoporosis in young haemophiliacs from western India. Am J Hematol 2007; 82(6): 453-7. doi: 10.1002/ajh.20877.

11. Barnes $C$, Wong $P$, Egan $B$, et al. Reduced bone density among children with severe hemophilia. Pediatrics 2004; 114: e17781. doi: 10.1542/peds.114.2.e177.

12. Mansouritorghabeh $H$, Rezaieyazdi Z, Saadati N, Saghafi M, Mirfeizi Z, Rezai J. Reduced bone density in individuals with severe hemophilia B. Int J Rheum Dis 2009; 12(2): 125-9. doi: 10.1111/j.1756-185X.2009.01394.x

13. Tlacuilo-Parra A, Villela-Rodriguez J, Garibaldi-Covarrubias R, Soto-Padilla J, Orozco-Alcala J. Bone turnover markers and bone mineral density in children with haemophilia. Haemophilia 2011; 17(4): 657-61. doi: 10.1111/j.13652516.2010.02439.x.

14. Abdelrazik N, Reda M, El-Ziny M, Rabea H. Evaluation of bone mineral density in children with hemophilia: Mansoura University children hospital (MUCH) experience, Mansoura, Egypt. Hematology 2007; 12(5): 431-7. doi: 10.1080/10245330701383700.

15. Naderi A, Nikvarz M, Arasteh M, Shokoohi M. Osteoporosis/ osteopenia and hemophilic arthropathy in severe hemophilic patients. Arch Iran Med 2012; 15: 82-4.

16. Wallny TA, Scholz DT, Oldenburg J, et al. Osteoporosis in haemophilia-an underestimated comorbidity? Haemophilia 2007; 13(1): 79-84. doi: 10.1111/j.1365-2516.2006.01405.x.

17. Gay ND, Lee SC, Liel MS, Sochacki P, Recht M, Taylor JA. Increased fracture rates in people with haemophilia: a 10-year single institution retrospective analysis. $\mathrm{Br} \mathrm{J}$ Haematol 2015; 170(4): 584-6. doi: 10.1111/bjh.13312.

18. Anagnostis P, Karras S, Pascho S, Goulis DG. Haemophilia A and $B$ as a cause for secondary osteoporosis and increased fracture risk. Blood Coagul Fibrinolysis 2015; 26(6): 599-603. doi: 1097/MBC.0000000000000330.

19. Ashritha A, Delhi Kumar CG, Sahoo J, Nalini P. Evaluation of bone mineral density in children with hemophilia: an observational case-control study. J Pediatr Hematol Oncol 2019; 41(7): 511-514. doi: 10.1097/ MPH.0000000000001554.

20. Sandeep Krishna A, Munirathnam T, Karthik A, Jagadeesh $G$, Karthick G. Osteoporosis in India - diagnosing in cost effective way - can digital X-ray with Singh's Index help? Ann Orthop Musculoskelet Disord 2019; 2(1): 1019 
21. Anagnostis $P$, Vakalopoulou $S$, Vyzantiadis T-A, et al. The clinical utility of bone turnover markers in the evaluation of bone disease in patients with haemophilia A and B. Haemophilia 2014; 20(2): 268-75. doi: 10.1111/hae.12271.

22. Singer FR, Eyre DR. Using biochemical markers of bone turnover in clinical practice. Cleve Clin J Med 2008; 75(10): 739-50. doi: 10.3949/ccjm.75.10.739.

23. Brown JP, Albert C, Nassar BA, et al. Bone turnover markers in the management of postmenopausal osteoporosis. Clin Biochem 2009; 42(10-11): 929-42. doi: 10.1016/j. clinbiochem.2009.04.001.

24. Feldman BM, Funk SM, Bergstrom B-M, et al. Validation of a new pediatric joint scoring system from the International Hemophilia Prophylaxis Study Group: validity of the hemophilia joint health score. Arthritis Care Res (Hoboken) 2011; 63(2): 223-30. doi: 10.1002/acr.20353.

25. Sun J, Hilliard PE, Feldman BM, et al. Chinese Hemophilia Joint Health Score 2.1 reliability study. Haemophilia 2014; 20(3): 435-40. doi: 10.1111/hae.12330.

26. Pettersson H, Ahlberg A, Nilsson IM. A radiologic classification of hemophilic arthropathy. Clin Orthop Relat Res 1980; (149): 153-9.
27. Ghosh K, Shetty S. Bone health in persons with haemophilia: a review. Eur J Haematol 2012; 89(2): 95-102. doi: 10.1111/j.1600-0609.2012.01803.x.

28. Poonnoose PM, Hilliard P, Doria AS, et al. Correlating clinical and radiological assessment of joints in haemophilia: results of a cross sectional study. Haemophilia 2016; 22(6): 925-33. doi: 10.1111/hae.13023.

29. Kang KY, Hong YS, Park S-H, Ju JH. Increased serum alkaline phosphatase levels correlate with high disease activity and low bone mineral density in patients with axial spondyloarthritis. Semin Arthritis Rheum 2015; 45(2): 202-7. doi: 10.1016/j. semarthrit.2015.03.002

HOW TO CITE THIS ARTICLE:

Mandal PK, Garg M, Chakrabarti P, Bhowmik A, Gantait D, Dolai TK. Bone health assessment in haemophilic arthropathy: A single centre study from Kolkata, West Bengal, India. J Haem Pract 2021; 8(1): 183-188. https:// doi.org/10.2478/ihp-2021-0018.

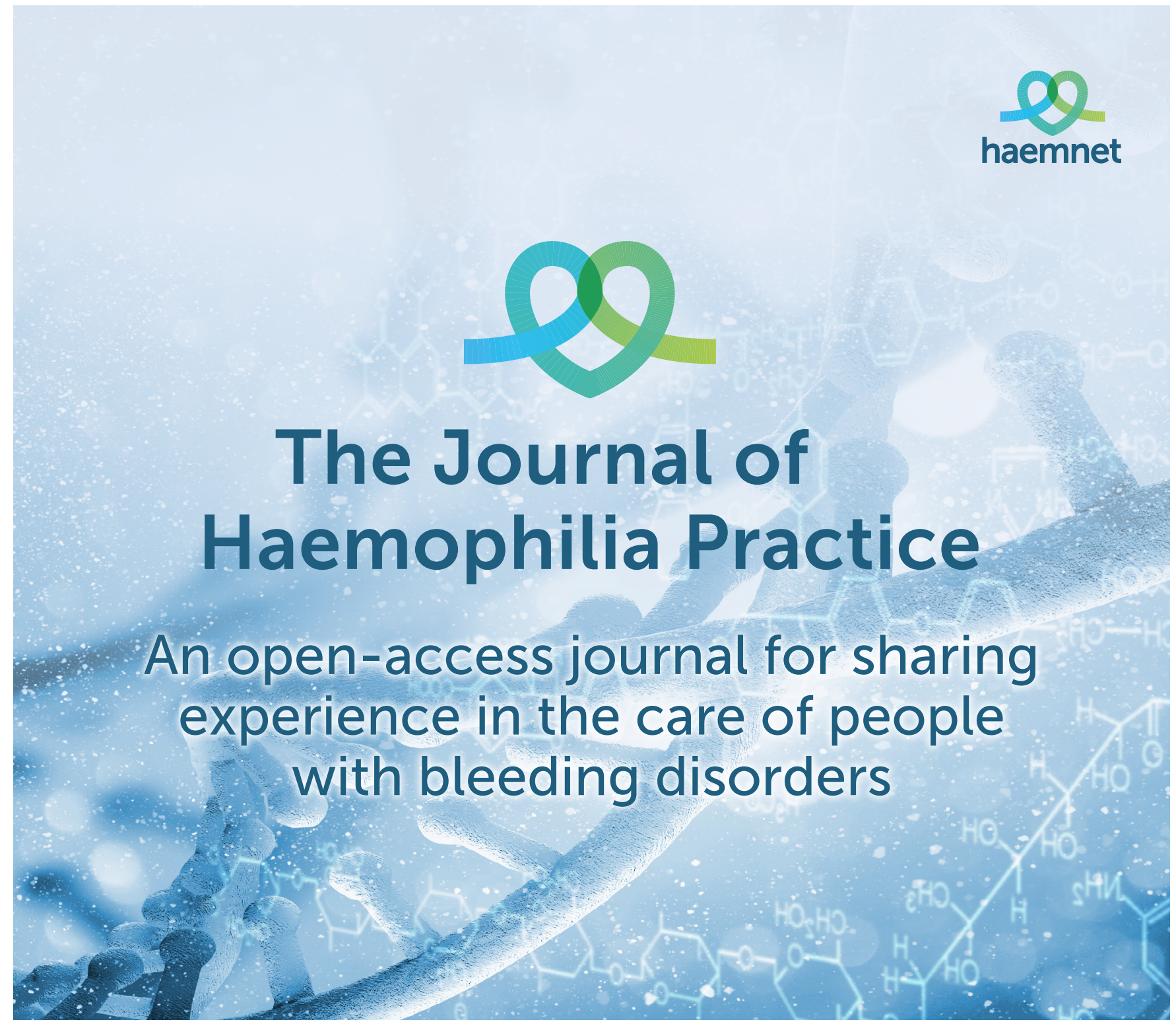

